\title{
Modulation and Control of Transformer less UPFC for Interconnecting Synchronous AC Grids
}

\author{
Mahendrakumar A. Pawar ${ }^{1}$ \\ ${ }^{1}$ Department of Electrical Engineering, Annasaheb Dange \\ College of Engineering and Technology, \\ Ashta-416301 \\ Swapnil D. Patil ${ }^{2}$ \\ ${ }^{2}$ Department of Electrical Engineering, Annasaheb Dange \\ College of Engineering and Technology, \\ Ashta-416301
}

\author{
Suraj D. Pawar ${ }^{3}$ \\ ${ }^{3}$ Department of Electrical Engineering, Annasaheb Dange \\ College of Engineering and Technology, \\ Ashta-416301. \\ Digvijay B. Kanase ${ }^{4}$ \\ ${ }^{4}$ Department of Electrical Engineering, Annasaheb Dange \\ College of Engineering and Technology, \\ Ashta-416301
}

\begin{abstract}
In this paper, Modulation and control of transformer less unified power flow controller is presented. As is well known the traditional UPFC that exists two back-to- back inverters bulky and more complicated zig-zag transformer are completely eliminated. Now a day's FACTS devices are used to control the flow of power to increase the transmission capacity and to improve the stability of the power system. One of the most commonly used FACTS devices is Unified power flow controller (UPFC). It is well that UPFC (Unified Power flow controllers) are the most versatile FACTS device that can be used to active power flow and reactive power flow control between synchronous grids. The convention UPFC that consist two back-to-back inverters are connecting with series and shunt transformers used for real power and reactive power exchange between grids to UPFC. In Transformer less new FACTS device are used to overcome the problem of convention UPFC such as the bulky, large size, zig-zag transformer, having slow dynamic response, isolation. Although the new transformer less UPFC to remove series and shunt transformers to achieve desired voltage. In case of Transformer we use inductor and capacitor combination series and shunt with $H$ Bridge power MOSFET Inverters. UPFC several advantages over the traditional technology ,such as Transformer less, light weight, high efficiency, low cost and fast dynamic response.
\end{abstract}

Keywords- Flexible AC Transmission System (FACTS), PWM (Plus width modulation), UPFC, Transformer less UPFC, Power flow control, LC Coupler.)

\section{INTRODUCTION}

The concept of unified power flow control is that injects voltage of variable magnitude and phase angle. This provides control of power system parameters, such as terminal voltage, line impedance and phase angle, thereby providing necessary real and reactive power flow control [1-2]. UPFC is a combination of STATCOM and SSSC, which are coupled via a common DC link [3], to allow bi-directional flow of real power between the series output terminals of the SSSC and shunt output terminals of STATCOM [4], and are controlled to provide concurrent real and reactive series line compensation without an external electric energy source [5$6]$.

UPFC is the most comprehensive multivariable Flexible AC Transmission system (FACTS) controller [7-9], UPFC is one of the FACTS devices, which can control power system parameters, such as terminal voltage, line impedance and phase angle [10]. Therefore it can be used not only for power flow control but also for power system stabilizing control UPFC capable of generating/absorbing both real and reactive power UPFC are capable of directing real and reactive power flow through a designated route [11]. Nowadays FACTS devices can be used to control the power flow and enhance system stability [12]. They enable a line to carry power closer to its thermal rating. The salient features of a FACTS device are its multiple control functions, such as power flow control, voltage control, transient stability enhancement and oscillation damping. Voltage sag compensation is necessary for secure system operation. A well designed FACTS Controller can not only increase the transmission capability but also improves the power system stability. UPFC is the most comprehensive multi variable flexible AC transmission systems controller (Menniti et. Al.2001 and Sen and Stacey 1999) [13].

\section{TRANFORMER LESS UPFC}

Fig.1 shows transformer less UPFC which consist with the help of CMI cascade multilevel inverter concept we used power MOSFET as inverter function Combination of series inductor and parallel capacitor to generate high voltage level. Coupling inductor is in between series and shunt combination of inductor and capacitor. Each phase having own dc source and each phase control with help of PWM (Pulse width Modulation) pulse width modulation signal given to the POWER MOSFET with modified signal.

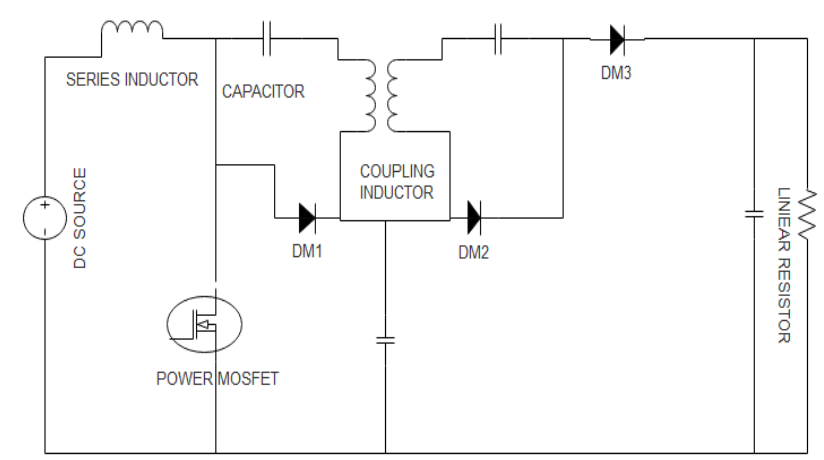

Fig.1. LC coupling inverter of transformer less Single phase UPFC

Each phase having own phase delay to maintain in transformer less UPFC with phase shifting between initial 
state and final state the control phase shift we also control voltage, current, real and reactive power with help of phase angel. The voltage control to the Vdg of power MOSFET used in each single phase control. Inductor and capacitor are connected in series and parallel are connecting with coupling inductor. Inductor is use in circuit for over current absorption inductor used for current controlling device and over power absorb. Initial inductor used for backup current flow through the coupling inductor protection. Capacitors are uses for generation of voltage, coupling inductor having same ratio to transfer real and reactive power of series and shunt connection. Negative current absorption we the help of absorption diodes also these diodes are use compensation diode and in phase diodes only.

\section{A. Transformer less UPFC Operating principle}

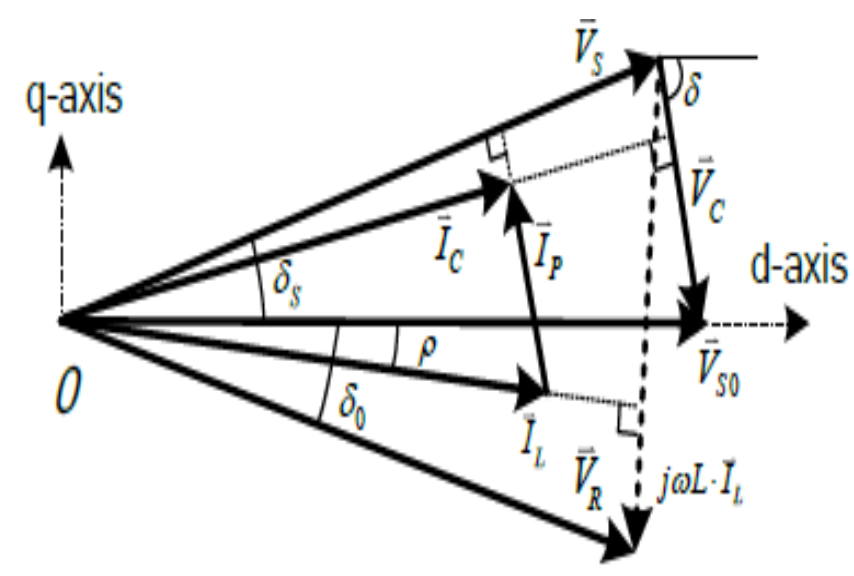

Fig.2. phasor diagram of transformer less UPFC

Fig.2 show a phase diagram example of the transformer less UPFC where $\mathrm{Vs} 0$ and Vro are the sending and receiving end voltages respectively. In transformer less UPFC generated voltage $\mathrm{Vc}$ for obtaining new sending end voltage Vs which in turn controls active and reactive power flows over the transmission line. Active power $\mathrm{P}$ and reactive power $\mathrm{Q}$ transmitted over the line with the UPFC can expressed Where $\delta 0$ is the original phase angle difference between the sending end voltage $V_{S O}$ and $V_{R O}$. The active power $P_{0}$ and reactive power $Q_{0}$ over the uncompensated system (without the UPFC) are:

$$
\begin{aligned}
& P_{0}=\frac{V_{S 0} V_{R} \sin \delta_{0}}{X} \\
& P_{0}=\frac{V_{S 0} V_{R} \sin \delta_{0}}{X}
\end{aligned}
$$

The active and reactive power $P_{C}$ and $Q_{C}$ of UPFC

$$
P_{C}=\frac{V_{C} V_{R} \sin \left(\delta_{0}+\delta\right)}{X}
$$

$$
Q_{C}=-\frac{V_{C} V_{R} \cos \left(\delta_{0}-\delta\right)}{X}
$$

Because both amplitude $V_{C}$ and phase angle del of the UPFC injected voltage phasor $V_{C}$ can be any values command the new UPFC provide a full controllable range for both active and reactive power Pc and Qc which are advantage independent of the original sending end voltage and phase angle therefore the theory proves that the new transformer less UPFC has the same functionally as the conventional UPFC.

\section{MATLAB SIMULATION OF THREE PHASE TRANSFORMER LESS UPFC}

Fig fig. 3 shows UPFC is used to control the power flow in a $500 \mathrm{kV} / 230 \mathrm{kV}$ transmission systems. The system, connected in a loop configuration, consists essentially of five buses (B1 to B5) interconnected through transmission lines (L1, L2, L3). Two power plants located on the $230-\mathrm{kV}$ system generate a total of $1500 \mathrm{MW}$ which is transmitted to a 500$\mathrm{kV}$ 15000-MVA equivalent and to a 200-MW load connected at bus B3. The plant models include a speed regulator, an excitation system as well as a power system stabilizer (PSS). In normal operation, most of the 1200-MW generation capacity of power plant.

Using the load flow option of the powergui block, the model has been initialized with plants 1 and 2 generating respectively $500 \mathrm{MW}$ and $1000 \mathrm{MW}$ and the UPFC Out of service (Bypass breaker closed). The resulting power flow obtained at buses B1 to B5 is indicated by red numbers on the circuit diagram. The UPFC Located at the right end of line L2 is used to control the active and reactive powers at the 500$\mathrm{kV}$ bus B3, as well as the voltage at bus B UPFC. It consists of a phasor model of two 100-MVA, MOSFET based, converters (one connected in shunt and one connected in series and both interconnected through a DC bus on the DC side and to the AC power system, through coupling reactors). Parameters of the UPFC Power components are given series converter can inject a maximum of $10 \%$ of nominal line-toground voltage $(28.87 \mathrm{kV})$ in series with line L2. The blue numbers on the diagram show the power flow with the UPFC in service and controlling the $\mathrm{B} 3$ active and reactive powers respectively at $300 \mathrm{MW}$ and -93 Mvar.

UPFC used for transmission line to measure Active and reactive power. There are two components UPFC Measurement and VPQ lines measurement in which Active power measurement and reactive power measurement as well as active power compensation and reactive power compensation in transmission line. We set in UPFC parameter block Reference values of $P Q_{\text {Reference }}$ and $V_{d q}$ initially in three phase voltage UPFC voltage as reference values. To control magnitude and phase angle compensate power to the grid line. 


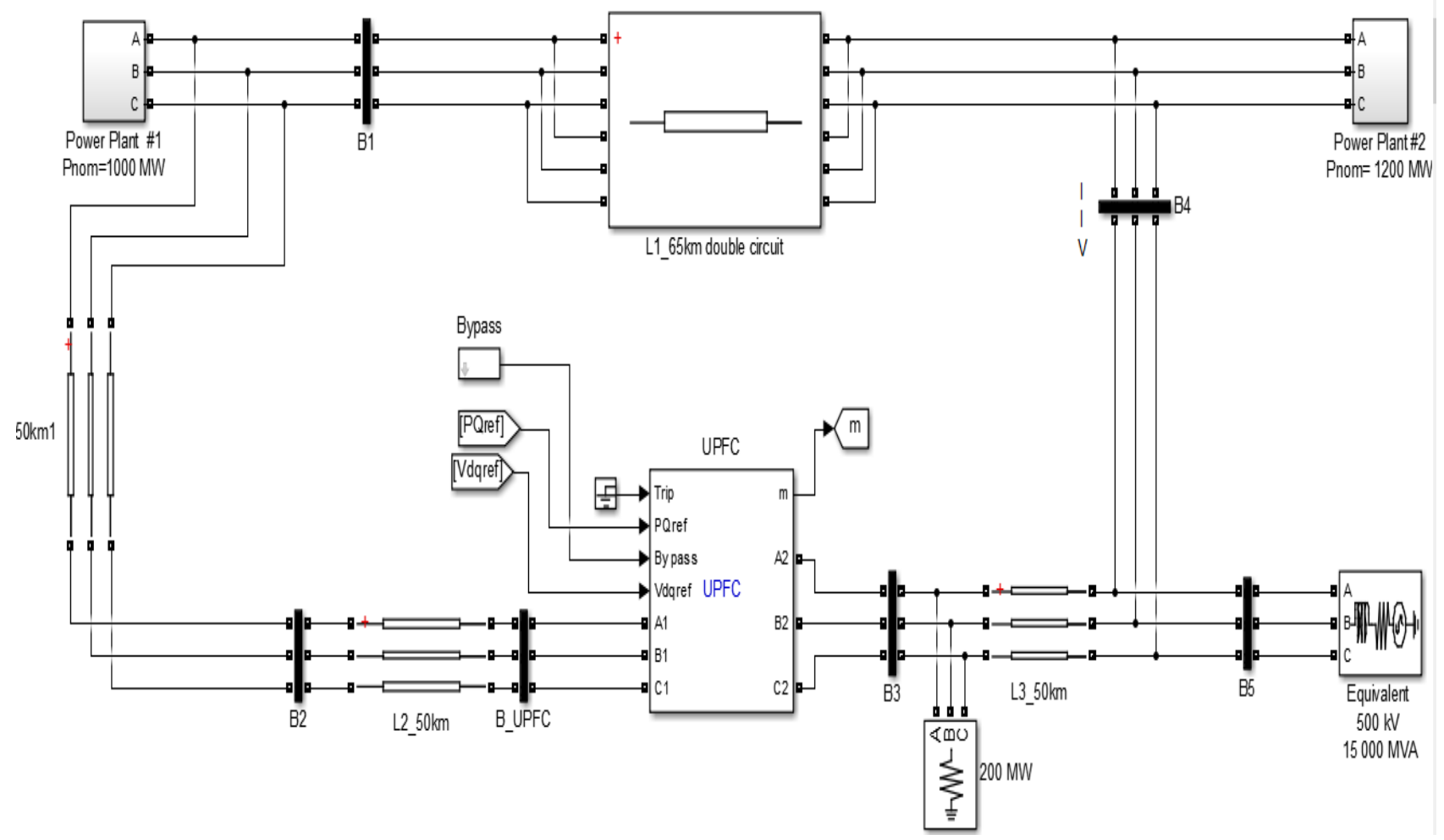

Fig.3. Three phase transformer less UPFC MATLAB Simulation

\section{A. Power control with the Transformer less UPFC}
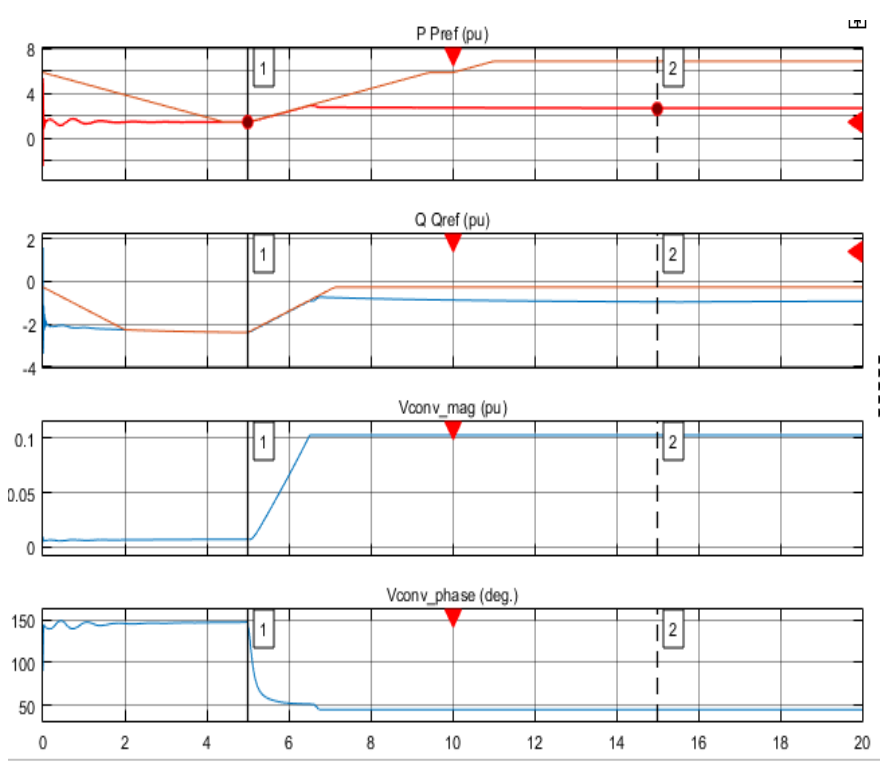

Fig.4. UPFC controllable parameters

\section{$P P_{\text {ref(pu) }} Q Q_{\text {reff(pu) }} V_{\text {como mag(pu) }}$ and $V_{\text {conv phase(deg.) }}$}

The UPFC reference active and reactive powers are set in the magenta blocks labeled "Pref(pu)" and "Qref(pu)". Initially the Bypass breaker is closed and the resulting natural power flow at bus B3 is $268 \mathrm{MW}$ and -93 Mvar. The Pref block is programmed with an initial active power of $5.87 \mathrm{pu}$ corresponding to the natural flow. Then, at $\mathrm{t}=10 \mathrm{~s}$, Pref is increased by $1 \mathrm{pu}(100 \mathrm{MW})$, from $5.87 \mathrm{pu}$ to $6.87 \mathrm{pu}$, while Qref is kept constant at -93 pu. Run the simulation and look on the UPFC scope how P and Q measured at bus B3 follow the reference values shown in fig. 4 .
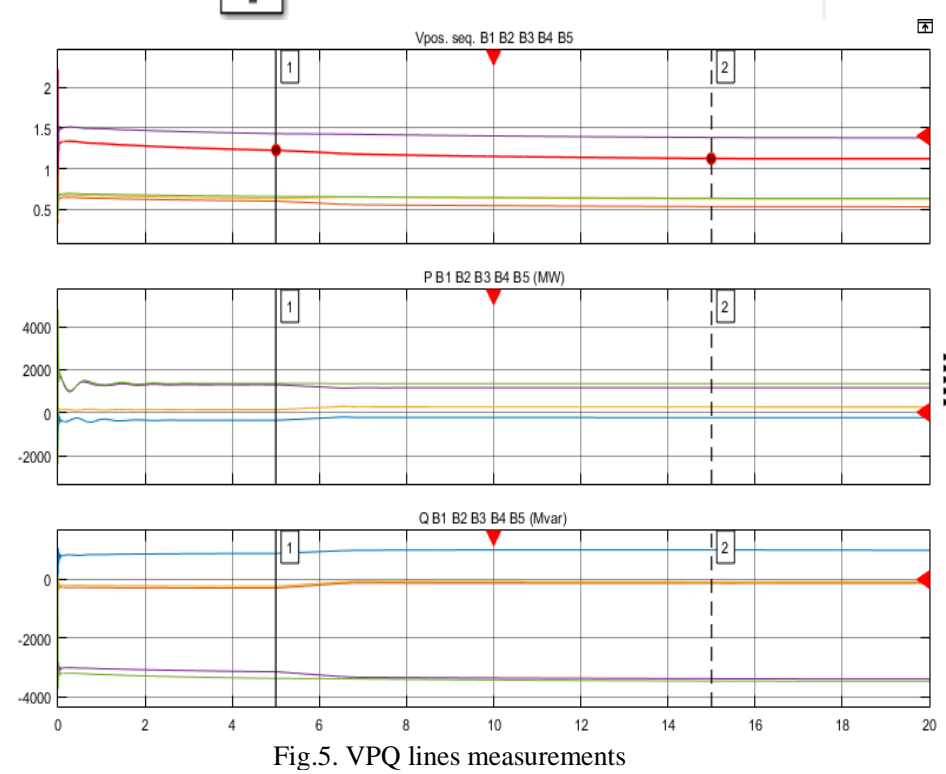

At $\mathrm{t}=5 \mathrm{~s}$, when the Bypass breaker is opened the natural power is diverted from the Bypass breaker to the UPFC series branch without noticeable transient. At $\mathrm{t}=10 \mathrm{~s}$, the power increases at a rate of $1 \mathrm{pu} / \mathrm{s}$. It takes one second for the power to increase to $900 \mathrm{MW}$. This $100 \mathrm{MW}$ increase of active power at bus B3 is achieved by injecting a series voltage of $0.089 \mathrm{pu}$. This results in an approximate $100 \mathrm{MW}$ decrease in the active power flowing from $268 \mathrm{MW}$ to $1400 \mathrm{MW}$, which now carries an acceptable load. See the variations of active powers at buses B1 to B5 on the "VPQ Lines" scope shown in fig. 5 .

\section{B. UPFC P-Q controllable region}

Now Show Control parameters (series converter). Select "Mode of operation= Manual Voltage injection". In this control mode the voltage generated by the series inverter is controlled by two external signals $V_{d q}$ multiplexed at the 
" $V_{\text {dqreff }}$ " input and generated in the $V_{\text {dqreff }}$, magenta block. For the first five seconds the Bypass breaker stays closed, so that the PQ trajectory stays at the (-93Mvar, $268 \mathrm{MW})$ point. Then when the breaker opens, the magnitude of the injected series voltage is ramped, from 0.0094 to $0.1 \mathrm{pu}$. At $10 \mathrm{~s}$, the angle of the injected voltage starts varying at a rate of 45 deg./s.

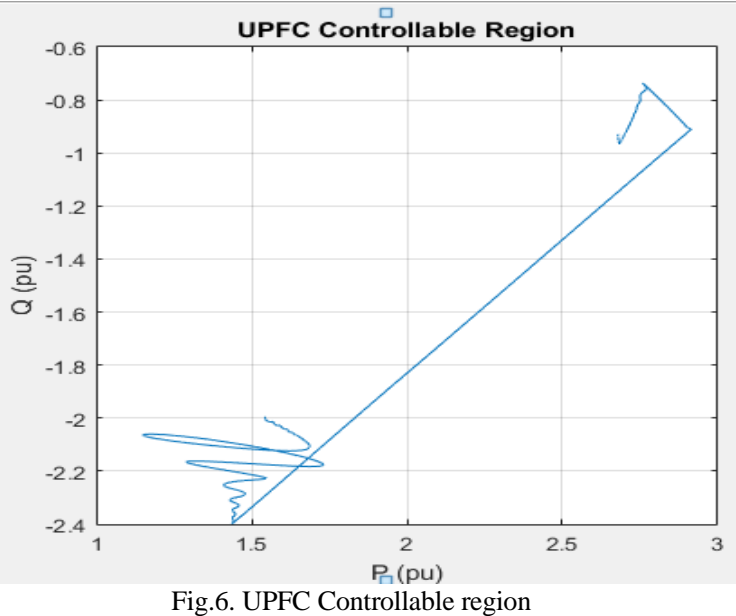

Initially $P P_{\text {ref(pu) }}$ set a particular pu values as $4-8 \mathrm{pu}$ values when UPFC connect in circuit the value of power flow will changes and to control active and reactive power flow demand without change in frequency. Compensation of active and reactive power in Transmission line about $10 \%$ of system voltage. To control voltage magnitude $V_{\text {conv_mag(pu) }}$ $(0 \leq 0.05 \leq 0.1)$ and $V_{\text {conw_phase(deg.) }}(0 \leq \delta \leq 45)$.

Table.1. VPQ Measurements

\begin{tabular}{|c|c|c|}
\hline Bus & Active Power (MW) & Reactive Power (MW) \\
\hline B1 & -217.8 & 978.1 \\
\hline B2 & 270.6 & -137.7 \\
\hline B3 & 268.1 & -93.01 \\
\hline B4 & 1168 & -3389 \\
\hline B5 & 1358 & -3466 \\
\hline
\end{tabular}

Run the simulation and look on the UPFC scope the P and $\mathrm{Q}$ signals that vary according to the changing phase of the injected voltage. At the end of the simulation, double-click on the blue block located at the bottom right of the model. The trajectory of the UPFC reactive power as function of its active power, measured at bus B3 will be displayed. Active and reactive power controllable region shown in fig.6.

\section{CONCLUSION}

The transformer less UPFC can realize the same function as convention UPFC without using transformer. It is expected that the transformer less UPFC Will have enormous technological and economic impacts on controlling the routing of energy over the existing power grid. Furthermore, the enabling technology of modularity and scalability makes it easy installation anywhere in the existing grid. UPFC damps the oscillations, improves reliability and proven to be cost effective. In future, Generalized Unified Power Flow Controller (GUPFC) will significantly extend the voltage and power flow capability, and offers a great potential in solving many of the problems facing the electric utilities these applications of innovative transformer less unified power controller (UPFC) interconnecting two synchronous AC grids.

\section{REFERENCES}

[1] F. Z. Peng, S. Zhang, S. T. Yang, D. Gunasekaran, and U. Karki, "Transformer-less unified power flow controller using the cascade multilevel inverter," in 2014 International Power Electronics Conference (IPEC-Hiroshima 2014 - ECCE-ASIA), 2014, pp. 1342 1349.

[2] N. G. Hingorani and L. Gyugyi, "Understanding FACTS: concept and technology of flexible AC transmission systems." 2000

[3] L. Gyugyi, C. D. Schauder, S. L. Williams, T. R. Rietman, D. R Torgerson, and A. Edris, "The unified power flow controller: a new approach to power transmission control," IEEE Transactions on Power Delivery, vol. 10, pp. 1085-1097, 1995.

[4] A. Rajabi-Ghahnavieh, M. Fotuhi-Firuzabad, M. Shahidehpour, and R. Feuillet, "UPFC for Enhancing Power System Reliability," IEEETransactions on Power Delivery, vol. 25, pp. 2881-2890, 2010.

[5] L. M. Liu, P.C. Zhu, Y. Kang, and J. Chen,"Power-Flow Control Performance Analysis of a Unified Power-Flow Controller in a NovelControl Scheme," IEEE Transactions on Power Delivery, vol. 22 pp. 1613-1619, 2007.

[6] S. Kannan, S. Jayaram, and M. M. A. Salama, "Real and reactive power coordination for a unified power flow controller," IEEE Transactions onPower Systems, vol. 19, pp. 1454-1461, 2004

[7] F. Z. Peng, J. S. Lai, J. W. McKeever, and J. VanCoevering, "A multilevel voltage-source inverter with separate DC sources for staticVAr generation," IEEE Transactions on Industry Applications, vol. 32, pp. 1130-1138, 1996

[8] S. T. Yang, Y. Liu, X. R. Wang, D. Gunasekaran, U. Karki, and F. Z. Peng, "Modulation and Control of Transformer-less UPFC," IEEE Transactions on Power Electronics, vol. PP, pp. 1-1, 2015.

[9] S. T. Yang, S. Zhang, X. R. Wang, D. Gunasekaran, and F. Z. Peng, "Optimization of fundamental frequency modulation for cascaded multilevel inverter based transformer-less UPFC," in 2014 IEEE Energy Conversion Congress and Exposition (ECCE), 2014, pp. 4647 4652

[10] Swapnil Patil, Khushal Shende, Anwar Mulla, Dadgonda Patil "TBSC Compensator"Chapter No. 22, Book Title Transactions on Engineering Technologies, Springer Singapore, DOI 10.1007/978-981-10-27178 22, Print ISBN 978-981-10-2716-1, Online ISBN 978-981-10-27178, Date: 07 February, 2017 pp 305-318.

[11] C. D. Schauder, L. Gyugyi, M. R. Lund, D. M. Hamai, T. R. Rietman, D. R. Torgerson, and A. Edris, "Operation of the unified power flow controller (UPFC) under practical constraints," IEEE Trans. Power Del., vol. 13, no. 2, pp. 630-639, 1998 .

[12] Swapnil Patil, Yogesh Shinde, Khushal Shende U. Gudaru, Senior Member IEEE, D. R. Patil Member,IAENG, "Transient Free TBSC Compensator for Dynamic Reactive Load with Closed Loop Control", Proceedings of the WCECS 2013 Vol I WCECS 2013, 23-25 October, 2013, San Francisco, USA.

[13] Rajkumari R. Patil ; Smita P. Patil ; Swapnil D. Patil ; Anwar M Mulla, "Designing of Z-source inverter for photovoltaic system using MATLAB/SIMULINK" International Conference on Circuit ,Power and Computing Technologies (ICCPCT), 2017, IEEE Conference Publications,

DOI: 10.1109/ICCPCT.2017.8074331
ISBN: 978-1-5090-4967-7, 